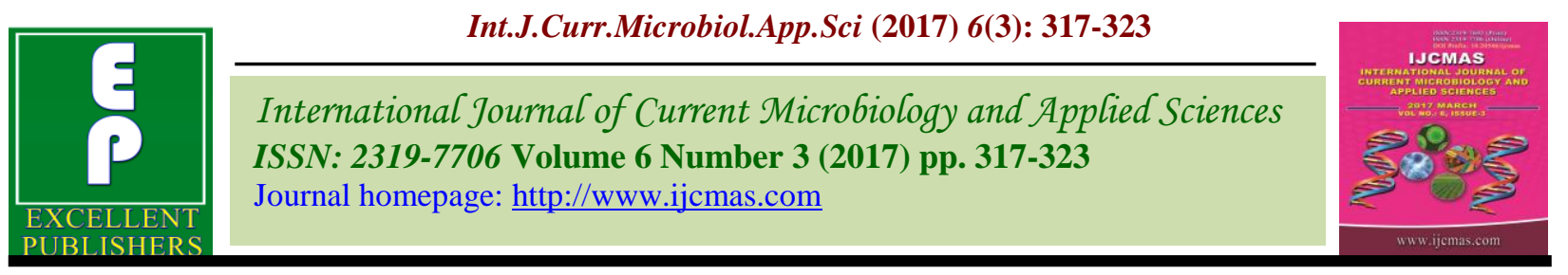

Original Research Article https://doi.org/10.20546/ijcmas.2017.603.035

\title{
A Simple Method for Transient Expression of Reporter Gene in Brinjal Leaves through Agroinfiltration
}

\author{
Vikash Kumar, Pawan Kumar and Tirthartha Chattopadhyay*
}

Department of Plant Breeding and Genetics, Bihar Agricultural College, Bihar Agricultural

University, Sabour, Bhagalpur, Bihar, India-813210

*Corresponding author

\section{A B S T R A C T}

\section{Ke y w o r d s \\ Agroinfiltration, Brinjal, \\ Histochemical assay, Reporter gene, Transient expression. \\ Article Info \\ Accepted: \\ 10 February 2017 \\ Available Online: \\ 10 March 2017}

\begin{abstract}
Brinjal (Solanum melongena L.) is one of the most important vegetable crops in India. In spite of the docility of brinjal towards genetic transformation through Agrobacterium, development of stable transgenic lines in brinjal is a cost, labour as well as time consuming process. On the other hand, the agro infiltration process has been optimized in different crops for the rapid analysis of transgene through transient expression. The process has also gained importance in synthetic biological applications for rapid production of therapeutic biomolecules in plants. Here, we have evaluated the agroinfiltration process in brinjal leaves through transient expression of a reporter gene driven by a constitutive promoter. Following optimization of the incubation period, proper infiltration medium and the optical density of the Agrobacterium suspension, we advocate the usefulness of the process for gene function analysis and other possible downstream applications through transient expression of a transgene in brinjal.
\end{abstract}

\section{Introduction}

The soil-borne bacterium, Agrobacterium tumefaciens is called the natural genetic engineer, because it has the capacity to transfer and integrate a part of its tumour inducing $(T i)$ plasmid DNA (the transfer DNA or T-DNA) into the plant genome. Through exploring this natural system, plant genetic engineers place their gene of interest in the engineered $T i$ plasmid and deliver the gene of interest through Agrobacterium. The robustness of the system has allowed the generation of numerous transgenic plants in a huge number of crop plants. However, Agrobacterium-mediated plant transformation for obtaining stable transgenic line is a timeconsuming process and depends on several factors. First of all, an efficient in vitro plant regeneration system (through tissue culture) for the target plant species appears as a prerequisite for Agrobacterium-mediated plant transformation. Most importantly, the site of integration of the transgene delivered by Agrobacterium is random in nature. Naturally, effect of the transgene in the transgenic plant is highly influenced by this 'position effect'. For this reason, a tissueculture independent system for initial evaluation of the transgene effect becomes very much pertinent in this regard.

The interaction between Agrobacterium and plant cell involves the transfer of the single 
stranded T-DNA containing the transgene, into the plant cell nucleus, where, integration of this transgene into the plant genome is the ultimate requirement for achieving a stable transgenic line.

Interestingly, the delivered but non-integrated transgene molecules remain transiently present in the nucleus. These molecules are capable of being transcribed and further processed to express the transgene in a transient manner (Kapila et al., 1997). More interestingly, expression given by these nonintegrated transgene molecules (i.e., the transient expression) is often $\sim 1000$ fold higher than the stable expression of the integrated transgene (Janssen and Gardner, 1989). Apart from this quantitative advantage, the transient expression system provides several other advantages, including, less requirement of time to analyse the effect of the transgene and freedom from the biased position effect (Kapila et al., 1997).

The transient expression system has been mostly used in planta through the process of syringe agroinfiltration, where a needleless syringe is used to deliver the Agrobacterium suspension through the lower surface of leaves in the intercellular spaces of the leaf. This method has been optimized in different crop species (Wroblewski et al., 2005)and has been successfully explored for diverse objectives, which include the study of gene silencing (Schöb et al., 1997; Johansen and Carrington, 2001), plant promoter analysis (Yang et al., 2000), plant $R$ and $A v r$ gene interactions (Van der Hoorn et al., 2000), recombinant protein production (Joh et al., 2005), rapid production of therapeutic agents in plant systems (Huang et al., 2006; Chen et al., 2013), gene function analysis (Hoffmann et al., 2006; Santos-Rosa et al., 2008), analysis of transcription factors (Berger et al., 2007), plant-based synthetic biology applications (Sainsbury and Lomonossoff, 2014) and many more.
In this study, we have analysed the utility of the agroinfiltration process in brinjal (Solanum melongena L.), one of the most important vegetable crops in India. Through Agrobacterium-mediated delivery of the $\beta$ glucuronidase (uidA/gusA) reporter gene under the transcriptional regulation of a constitutive promoter, we have analyzed the optimum incubation time, suitable infiltration medium and optimum bacterial concentration in order to achieve sufficient transient expression of transgene through agroinfiltration in brinjal leaves.

\section{Materials and Methods}

\section{Plant material}

Fully expanded leaves of 28-35 days' old brinjal (cv. Pant Rituraj) seedlings were used for agroinfiltration in the present study.

\section{Plasmid and bacterial strain}

The $p C A M: 2 X$-gusA recombinant plasmid (Chattopadhyay et al., 2011) was used in the present study. This recombinant plasmid is derived from the pCAMBIA1391z promoterprobe vector, which contains the $\beta$ glucuronidase (uidA/gusA) reporter gene downstream of the multiple cloning site (MCS). The engineered uidA/gusA gene of this vector contains a catalase intron, which ensures that reporter gene expression is seen only after eukaryotic processing and not from the prevailing bacterial cells, if any. The pCAM:2X-gusA recombinant plasmid contains the enhanced $(2 X)$ cauliflower mosaic virus (CaMV) $35 \mathrm{~S}$ promoter, cloned in MCS region of the plasmid to drive the constitutive expression of the uidA/gusA reporter gene. This recombinant plasmid was mobilized into chemically competent Agrobacterium tumefaciens strain LBA 4404/virGN54D (Fits et al., 2000) cells. The positive Agrobacterium clones harbouring the 
recombinant plasmid were selected on LuriaBertani (LB) agar plates containing $20 \mathrm{mgl}^{-1}$ rifampicin, $75 \mathrm{mgl}^{-1}$ chloramphenicol and 50 $\mathrm{mgl}^{-1}$ kanamycin antibiotics.

\section{Agroinfiltration procedure}

Loop-full culture of Agrobacterium clone harbouring the recombinant plasmid ( $p C A M: 2 X-g u s A$ ) was inoculated in $3 \mathrm{ml}$ of LB medium, containing $20 \mathrm{mgl}^{-1}$ rifampicin, $75 \mathrm{mgl}^{-1}$ chloramphenicol and $50 \mathrm{mgl}^{-1}$ kanamycin antibiotics and allowed for overnight growth in a shaker at $28{ }^{\circ} \mathrm{C}$. Next day, $100 \mu \mathrm{l}$ of the saturated Agrobacterium culture was again inoculated in $5 \mathrm{ml}$ of LB media, containing $20 \mathrm{mgl}^{-1}$ rifampicin, 75 $\mathrm{mgl}^{-1}$ chloramphenicol and $50 \mathrm{mgl}^{-1}$ kanamycin antibiotics and allowed for overnight growth in a shaker at $28^{\circ} \mathrm{C}$. The optical density at $600 \mathrm{~nm}$ wavelength $\left(\mathrm{OD}_{600}\right)$ of this culture was checked through spectrophotometry, and the cells of the culture were precipitated through centrifugation (6000 RPM for $5 \mathrm{~min}$ ) at room temperature. The harvested cell pellet was resuspended in appropriate volume of infiltration medium [i.e., sterile water or $5 \%(\mathrm{w} / \mathrm{v})$ sucrose or $1 / 2$ strength Murashige and Skoog (MS) liquid medium ( $\mathrm{pH} 5.2$ ) or $1 / 2$ strength $\mathrm{MS}$ liquid medium ( $\mathrm{pH} 5.2$ ) containing $20 \mathrm{mM} \mathrm{CaCl}_{2}$ ] to achieve different $\mathrm{OD}_{600}$ values of this final suspension.

The final Agrobacterium suspension was used for agroinfiltration of the brinjal leaves. For this purpose, the suspension was infiltrated in the lower surface of the brinjal leaves through a needle-less $2 \mathrm{ml}$ syringe. Infiltration of the Agrobacterium suspension was clearly indicated by dark green colouration of the infiltrated leaf part.

\section{Histochemical assay}

Histochemical assay for $\beta$-glucuronidase (GUS) activity was carried out as per standard method (Jefferson et al., 1987). Leaf discs from the infiltrated parts were punched through a punching machine and collected in $0.5 \mathrm{ml}$ microcentrifuge tubes. The leaf discs were submerged in the assay buffer $[50 \mathrm{mM}$ sodium phosphate buffer, $\mathrm{pH} 7.2,0.2 \%(\mathrm{v} / \mathrm{v})$ triton $\mathrm{X}-100,2 \mathrm{mM}$ potassium ferrocyanide, 2 $\mathrm{mM}$ potassium ferricyanide and $2 \mathrm{mM} 5-$ bromo-4-chloro-3-indolyl $\beta$-D-glucuronide (X-Gluc)] and kept at $37{ }^{\circ} \mathrm{C}$ incubator. After appearance of the characteristic blue colour conferred by the reporter gene expression, the leaf discs were dechlorophyllized in $70 \%$ ethanol and imaged.

\section{Results and Discussion}

\section{Effect of incubation period}

Transient expression of the $\beta$-glucuronidase (uidA/gusA) reporter gene was first analyzed after different time intervals from the agroinfiltration process to optimize the proper incubation period. The transient expression of the reporter gene, as revealed by histochemical assay of the agroinfiltrated leaf parts, was found to be the maximum after 3 days of infiltration (Fig. 1). The expression was observed till 5 days after agroinfiltration, which ultimately reduced to become almost invisible after 7 days of agroinfiltration. This result is quite expected, as, in most of the cases, generally, the transient expression of transgene has been reported to be evaluated 45 days after infiltration (Wroblewski et al., 2005).

\section{Effect of different infiltration medium}

Selection of a suitable infiltration medium has been documented to be an important parameter for gene delivery in plant systems (McIntosh et al., 2004; Tague and Mantis, 2006; Du et al., 2010). Hence, in the present study, the effect of different media used for agroinfiltration was further analyzed through histochemical assay of the agroinfiltrated leaf 
parts after 3 days of infiltration. It was found that even sterile water, when used as the infiltration medium, was sufficient to produce transient gene expression. However, 5\% (w/v) sucrose solution as well as $1 / 2$ strength MS liquid medium might be considered better, if uniformity of transient expression is considered (Fig. 2). Use of 5\% (w/v) solution has also been found to be suitable for transient gene expression assay in Anthurium (Hosein et al., 2012). Supplementation of 20 $\mathrm{mM} \mathrm{CaCl} 2$ in $1 / 2$ strength MS medium did not improve the level of transient expression.

\section{Effect of optical density of the} Agrobacterium suspension

The concentration of the Agrobacterium suspension used for gene delivery has been regarded as a significant factor in plant transformation, as reported earlier (SantosRosa et al., 2008; Kim et al., 2009; Fitch et al., 2011). So, the effect of the final optical density $\left(\mathrm{OD}_{600}\right)$ of the Agrobacterium suspension in $5 \%(\mathrm{w} / \mathrm{v})$ sucrose solution used for agroinfiltration was further analyzed in a similar manner after 3 days of agroinfiltration. For this purpose, different Agrobacterium suspensions with a wide range of $\mathrm{OD}_{600}$ values (i.e., 0.2 to 3.2) were used and transient expression of the reporter gene was evaluated. It was observed that, even the Agrobacterium suspension with $\mathrm{OD}_{600} \sim 0.2$ was sufficient for transient expression of the reporter gene. However, better uniform expression of reporter gene was recorded when Agrobacterium suspension with $\mathrm{OD}_{600}$ $\sim 1.6$ was used (Fig. 3). This result is in corroboration with previous similar studies in Anthurium (Hosein et al., 2012) and tomato (Gao et al., 2009), where Agrobacterium suspension with $\mathrm{OD}_{600} \sim 1.5$ has been found to be most efficient. The Agrobacterium suspension with $\mathrm{OD}_{600}>1.6$ was not found to further improve the transient expression of the reporter gene, as observed in the present study.

Fig.1 Histochemical assay for transient expression of gusA reporter gene in non-infiltrated (control) leaf disc and agroinfiltrated leaf discs of brinjal after different incubation periods

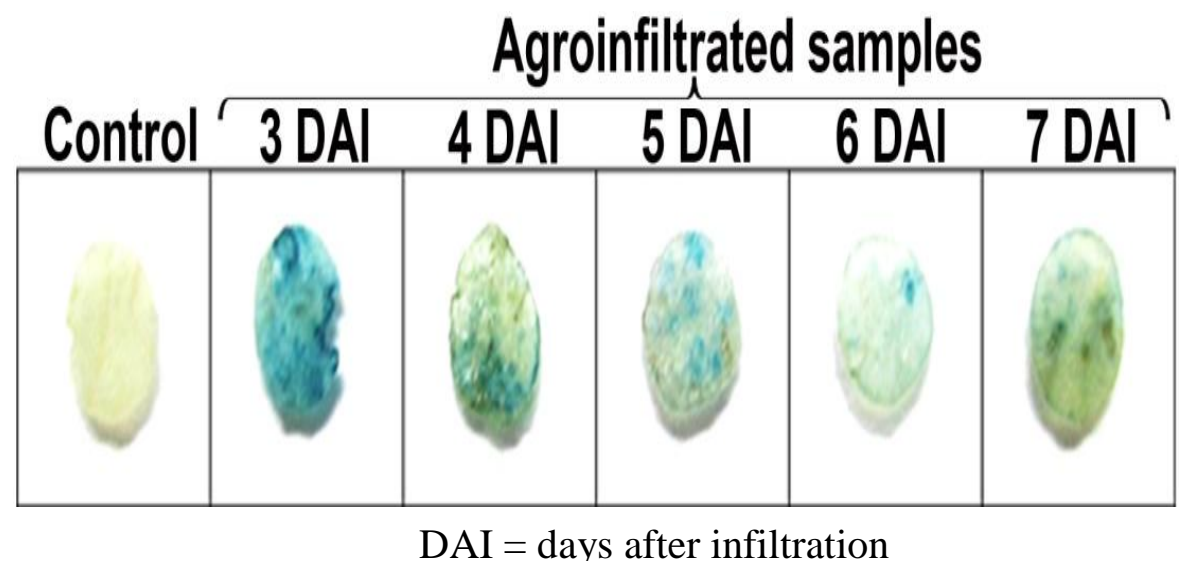


Fig.2 Histochemical assay for transient expression of gusA reporter gene in agroinfiltrated leaf discs of brinjal, where different infiltration medium was used. S1, S2, S3 = three independent leaf discs from different agroinfiltrated zones of the leaves

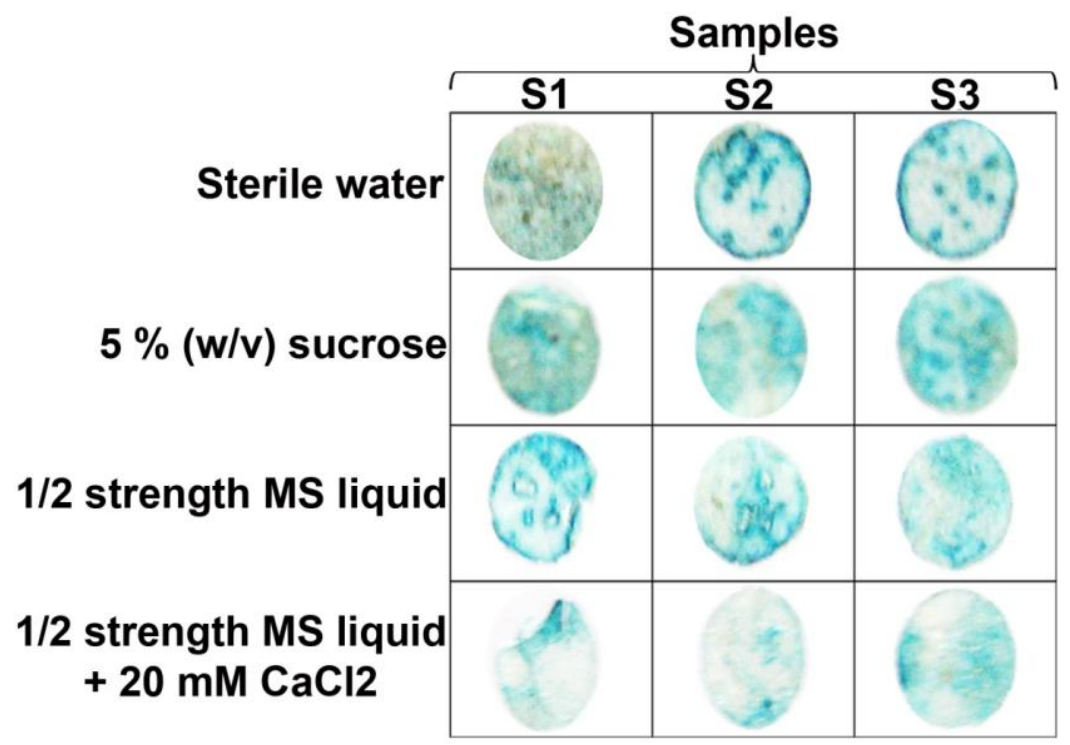

Fig.3 Histochemical assay for transient expression of gusA reporter gene in agroinfiltrated leaf discs of brinjal, where Agrobacterium suspension of different concentrations (i.e., with different $\mathrm{OD}_{600}$ values) were used. S1, S2, S3 = three independent leaf discs from different agroinfiltrated zones of the leaves

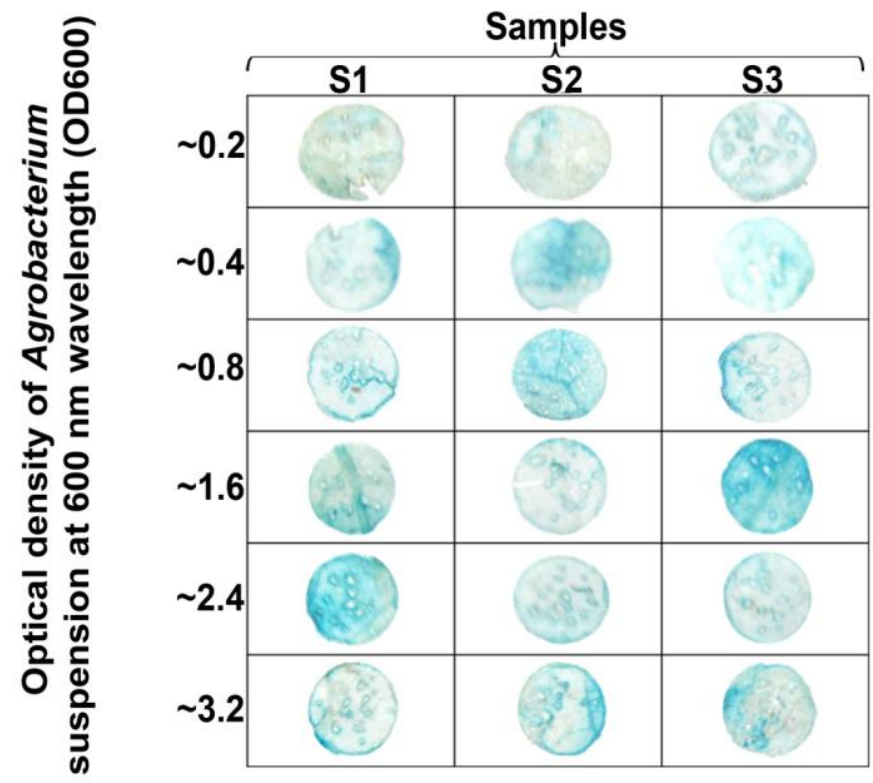

In this study, we have reported a simple method that allows transient expression of a transgene in brinjal leaves, following agroinfiltration. Being an important vegetable crop, brinjal demands attention of the researchers involved in the field of plant molecular biology. The method reported here should be rendered very much useful for rapid functional analysis of 
different genes of brinjal and may indicate the possibility of heterologous gene expression in brinjal system. For example, the efficacy of an uncharacterized gene towards insect resistance in brinjal might be analyzed through agroinfiltration (as described in this study) of a suitable gene construct followed by insect bioassay with the infiltrated leaf part. It is important to mention here that, agroinfiltration in tomato has been reported to induce tissue necrosis (Van der Hoorn et al., 2000) and a similar type of necrotic response has been predicted for other solanaceous crops (Wroblewski et al., 2005). However, in the present study, no significant tissue necrosis following agroinfiltration was noticed. Hence, we advocate the agroinfiltration method, reported in this study, to be adopted for analysis of transient gene expression in brinjal plant system. Furthermore, owing to the simplicity and robustness of the agroinfiltration technique, the method might be evaluated for other possible downstream applications through transient expression of a transgene in brinjal.

\section{Acknowledgement}

The authors thank Prof. M.K. Maiti, Department of Biotechnology, Indian Institute of Technology Kharagpur, West Bengal, India for providing the $p C A M: 2 X$-gusA recombinant plasmid and the Agrobacterium tumefaciens strain LBA 4404/virGN54D). VK and PK thank Department of Science and Technology, Government of India and BAU, Sabour, respectively for providing fellowship. Financial assistance from the Department of Science and Technology, Govt. of India in terms of project grant (Project code: SB/YS/LS-74/2013) is acknowledged. The authors thank Dr. P.K. Singh, Chairman, Department of Plant Breeding and Genetics, BAC, BAU, Sabour for providing valuable suggestions. This article bears BAU Communication No.: 223/2017.

Competing interest: Authors have no competing interest regarding publication of manuscript.

\section{References}

Berger, B., Stracke, R., Yatusevich, R., Weisshaar, B., Flügge, U. and Gigolashvili, T. 2007. A simplified method for the analysis of transcription factorpromoter interactions that allows highthroughput data generation. Plant J., 50: $911-916$.

Chattopadhyay, T., Roy, S., Mitra, A. and Maiti, M.K. 2011. Development of a transgenic hairy root system in jute (Corchoruscapsularis L.) with gusA reporter gene through Agrobacterium rhizogenes mediated co-transformation. Plant Cell Rep., 30: 485 - 493.

Chen, Q., Lai, H., Hurtado, J., Stahnke, J., Leuzinger, K. and Dent, M. 2013. Agroinfiltration as an effective and scalable strategy of gene delivery for production of pharmaceutical proteins. Adv. Tech. Biol. Med., 1: 103. doi:10.4172/atbm.1000103.

Du, H., Wu, H., Yang, J. and Li, J. 2010. Effects of basal media, salt concentrations, antioxidant supplements and co-effects on the Agrobacterium-mediated transformation efficiency in maize. Afr. J. Biotechnol., 9: $1135-1143$.

Fitch, M.M.M., Leong, T.C.W., McCafferty, H.R.K., Zhu, Y.J., Moore, P.H., Gonsalves, D., Aldwincle, H.S. and Atkinson, H.J. 2011.Improved transformation of Anthurium, HortSci., 46: 358 - 364.

Fits, L., Deakin, E.A., Hoge, J.H.C. and Memelink, J. 2000. The ternary transformation system: constitutive $\operatorname{vir} G$ on a compatible plasmid dramatically increases Agrobacterium-mediated plant transformation, Plant Mol. Biol., 43: 495 502.

Gao, N., Shen, W., Cao, Y., Su, Y. and Shi, W. 2009. Influence of bacterial density during preculture on Agrobacterium-mediated transformation of tomato. Plant Cell Tissue Organ Cult., 98: 321-330.

Hoffmann, T., Kalinowski, G. and Schwab, W. 2006.RNAi-induced silencing of gene expression in strawberry fruit (Fragaria $x$ ananassa) by agroinfiltration: a rapid assay for gene function analysis. Plant J., 48: 818-826. 
Hosein, F.N., Lennon, A.M. and Umaharan, P. 2012. Optimization of an Agrobacteriummediated transient assay for gene expression studies in Anthuriumandraeanum. J. Amer. Soc. Hort. Sci., 137: $263-272$.

Huang, Z., Santi, L., LePore, K., Kilbourne, J., Arntzen, C.J. and Mason, H.S. 2006. Rapid, high-level production of hepatitis B core antigen in plant leaf and its immunogenicity in mice. Vaccine, 24: 2506 - 2513.

Janssen, B.J. and Gardner, R.C. 1989. Localized transient expression of GUS in leaf discs following cocultivation with Agrobacterium. Plant Mol. Biol., 14: 6172.

Jefferson, R.A., Kavanagh, T.A. and Bevan, M.W. 1987. GUS fusion: $\beta$-Glucuronidase as a sensitive and versatile gene fusion marker in higher plants. EMBO J., 6; 3901-3907.

Joh, L.D., Wroblewski, T., Ewing, N.N. and Vander Gheynst, J.S. 2005. High-level transient expression of recombinant protein in lettuce. Biotechnol. Bioeng., 91; 861871.

Johansen, L.K. and Carrington, J.C. 2001. Silencing on the spot.Induction and suppression of RNA silencing in the Agrobacterium-mediated transient expression system. Plant Physiol., 126: 930 $-938$.

Kapila, J., DeRycke, R., Van Montagu, M. and Angenon, G. 1997.An Agrobacteriummediated transient gene expression system for intact leaves. Plant Sci., 122: $101-108$.

Kim, M.J., Baek, K. and Park, C.M. 2009. Optimization of conditions for transient Agrobacterium-mediated gene expression assays in Arabidopsis. Plant Cell Rep., 28: 1159 - 1167.
McIntosh, K.B., Hulm, J.L., Young, L.W. and Bonham-Smith, P.C. 2004.A rapid Agrobacterium-mediated Arabidopsis thaliana transient assay system. Plant Mol. Biol. Rep., 22: 53 - 61 .

Sainsbury, F. and Lomonossoff, G.P. 2014.Transient expressions of synthetic biology in plants, Curr. Opin. Plant Biol., 19: $1-7$.

Santos-Rosa, M., Poutaraud, A., Merdinoglu, D. and Mestre, P. 2008.Development of a transient expression system in grapevine via agro-infiltration, Plant Cell Rep., 27: 1053 -1063 .

Schöb, H., Kunz, C. and Meins (Jr), F. 1997. Silencing of transgenes introduced into leaves by agroinfiltration: a simple, rapid method for investigating sequence requirements for gene silencing, Mol. Gen. Genet., 256: $581-585$.

Tague, B.W. and Mantis, J. 2006. In planta Agrobacterium-mediated transformation by vacuum infiltration. Methods Mol. Biol., 232: $215-223$.

Van der Hoorn, R.A.L., Laurent, F., Roth, R. and De Wit, P.J.G.M. 2000. Agroinfiltration is a versatile tool that facilitates comparative analyses of $A v r 9 / c f$-9-induced and $A v r 4 / C f$ 4-induced necrosis. Mol. Plant-Microbe Interact., 13: 439 - 446.

Wroblewski, T., Tomczak, A. and Michelmore, R. 2005.Optimization of Agrobacterium mediated transient assays of gene expression in lettuce, tomato and Arabidopsis. Plant Biotech. J., 3: 259 273.

Yang, Y., Li, R. and Qi, M. 2000. In vivo analysis of plant promoters and transcription factors by agroinfiltration of tobacco leaves. Plant J., 22: $543-551$.

\section{How to cite this article:}

Vikash Kumar, Pawan Kumar and Tirthartha Chattopadhyay. 2017. A Simple Method for Transient Expression of Reporter Gene in Brinjal Leaves through Agroinfiltration. Int.J.Curr.Microbiol.App.Sci. 6(3): 317-323. doi: https://doi.org/10.20546/ijcmas.2017.603.035 